\title{
From the Editor of Sexuality and Disability: The Search to Increase Awareness and Perspective
}

\author{
Sigmund Hough ${ }^{1}$
}

Published online: 4 August 2017

(C) Springer Science+Business Media, LLC 2017

As many are aware, one measure of a journal can be the Impact Factor. We are happy to report that our Impact Factor increased to Impact Factor: 0.908 (2016), Journal Citation Reports $^{\circledR}$. We take time to appreciate and send a personal "THANK YOU" for the efforts and dedication from Springer and Staff, Editorial Board members and Reviewers, Authors, and Readership. The interest and commitment of an international team effort continues as a strength in the field of sexuality and disability.

The journal of Sexuality and Disability remains a professional home for many, and a place of professional rejuvenation and exploration for still more. If you are new to the journal, we give to you a "BIG WELCOME" to participate as a reader, author, academician, clinician, educator, service provider, researcher, advocate, and individual or individuals seeking information. Over decades of contribution to the literature on sexuality and disability, we have been a part of the growth and understanding. Now most importantly, we continue to be a part of change in how we look and examine the topic, the need, and the response in terms of best practice- evidence based approaches. With the intelligence, experience, motivation and commitment from our authors, readership, peer reviewers and editorial board, and resources with guidance from the Springer Staff, our journal's mission continues to be strong and meaningful.

Sexuality and Disability continues to provide original impact articles addressing the mental health and medical aspects of sexuality in relation to rehabilitation, hospital, academic and community settings, publishing up-to-date articles, case studies, clinical practice reports, reviews, featured articles, historical articles, special grand rounds topics, brief research reports and survey data reports. Value benefit is provided to authors through worldwide electronic exposure and professional access, while readership gains from scholarly contributions to advance the field through research, best-practice and educational

Sigmund Hough

Sigmund_Hough@hms.harvard.edu

1100 Cummings Center, Suite 207, Beverly, MA 01915-6144, USA 
articles. The refined lens of individual contributions from the local and international community continues to deliver a wealth of information on the topic of sexuality and disability for the reader. Thank you for joining our professional community. 